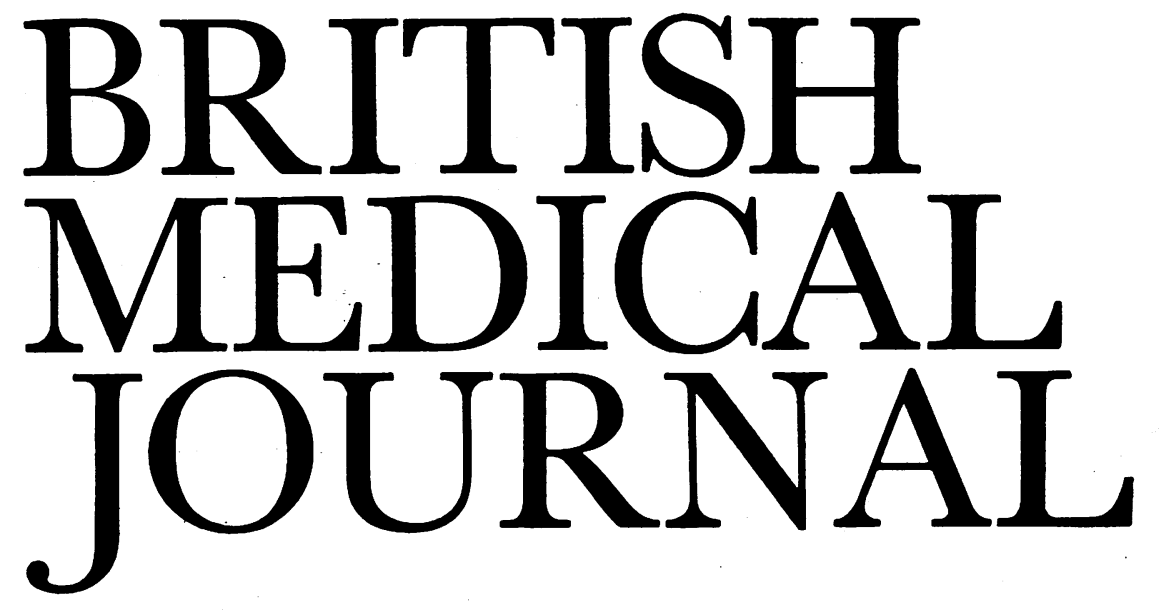

LONDON, SATURDAY 4 APRIL 1987

\title{
Age and infertility
}

Measuring the effect of age on fertility is difficult because so many people use artificial methods to control fertility. Data from Western communities employing no artificial methods, such as the Hutterites of North America, show a gradual decline in fertility with age, which becomes steeper after 40 and approaches zero by $49 .{ }^{12}$ Increasing age of the man, reduced coital frequency, ${ }^{3}$ and increasing duration of marriage ${ }^{4}$ may all influence this decline, but data from a community where late marriage was common showed a similar pattern: $16 \%$ of women married between 30 and 34 remained childless, as did $31 \%$ of those marrying between 35 and 39 and $69 \%$ of those marrying over $40 .^{3}$

These studies may not be relevant to women in contemporary society, where contraceptive practices allow early sexual activity with the option of delaying pregnancy for up to 20 years. During this time pelvic infection may reduce the chances of a future planned pregnancy. ${ }^{56}$ Tubal disease is not, however, an important cause of infertility ${ }^{78}$ and there is no evidence that the prolonged use of oral contraception is detrimental to fertility. ${ }^{9}$ Indeed, it may protect against certain disorders associated with rising age and nulliparity, such as uterine fibroids. ${ }^{10}$ Of more concern is the idea that fecundity is declining in both men and women because of adverse environmental factors. ${ }^{611}$ These would predominantly affect older women because of the prolonged exposure of their oocytes to such influences, but deteriorations in semen characteristics have also been reported. ${ }^{12}$ The study by Johnson $e t$ al is reassuring because it does not show a rise in involuntary infertility with age, although no information is available about women who may deliberately defer childbearing until after 35 (28 March, p 804).

Any adverse effect of aging would increase the number of couples presenting with "unexplained" infertility, and analysis of conception rates among couples thus classified confirms that the prognosis is inversely related to the age of the women at presentation. ${ }^{913}$ There is no evidence, however, that couples with unexplained infertility are any older at presentation than those in other diagnostic groups, ${ }^{14}$ and age did not significantly affect prognosis for couples in these other categories. ${ }^{15} 16$

In such studies it is difficult to control for an effect of aging in the man. Semen collected from men of proved fertility undergoing routine analysis before vasectomy or for screening as potential donors in artificial insemination by donor programmes shows an age related decline in sperm motility and morphological characteristics. ${ }^{17}$ One study controlled for male factors and coital frequency by looking at women with azoospermic husbands who were artificially inseminated ${ }^{18}$ : a cumulative conception rate of $73 \%$ after 12 months in women aged 30 and under fell to $63 \%$ in those between 31 and 35 and to $54 \%$ in those over 35 . Though supporting a decline in fecundity with age, these figures do not allow for the increase in conception time that occurs with age $^{4}$; they are also likely to underestimate the chances of conception in all age groups because of the nature of the treatment and the use of cryopreserved semen.

There is thus considerable evidence for a decline in fecundity with age, but the reasons for this are not clear. About $80 \%$ of women between 40 and 50 who are still menstruating continue to ovulate. ${ }^{19}$ Data from one study on fertilisation in vitro showed that failure of implantation and early spontaneous abortion rose with age, ${ }^{20}$ which is compatible with the theory that reduced fecundity in older women is caused by the loss of chromosomally abnormal conceptuses $^{21}$ rather than a defect in fertilisation itself. Another study of in vitro fertilisation showed, however, that pregnancy rates in those aged 36 to 39 were higher than in younger women, and there was no sharp decline in those over 40 (although only a few women were this old)..$^{22}$ This may support alternative theories that the reduction in fecundity with age is related to abnormal endocrine factors or to delayed fertilisation combined with reduced coital frequency. ${ }^{21}$ Under ideal conditions the effect of age on the chance of achieving a successful pregnancy may be less than previous studies have led us to believe.

The authors of a recent review have concluded that women who defer childbearing until their early 30 s risk no more than a biological decline in their fecundity that is no worse than that quoted in the early studies provided that they have avoided the hazards of early sexual activity. ${ }^{2323}$ Advancing age is not a major factor in infertility, and couples should not be excluded from investigation and treatment on the grounds of age alone.

Senior Lecturer,

Christine P West

Department of Obstetrics and Gynaecology,

Centre for Reproductive Biology,

University of Edinburgh,

Edinburgh EH3 9EW 
1 Eaton JW, Mayer AJ. The social biology of very high fertility among the Hutterites: the demography of a unique population. Hum Biol 1953;25:206-64.

2 Tietze C. Reproductive span and rate of reproduction among Hutterite women. Fertil Steril 1957;8:89-97.

3 Guttmacher AF. Factors affecting normal expectation of conception. JAMA 1939;161:855-60. 4 Tietze C, Guttmacher AF, Rubin S. Time required for conception in 1721 planned pregnancies. Fertil Steril 1950;1:338-46.

5 Westrom $L$. Incidence, prevalence and trends of acute pelvic inflammatory disease and its consequences in industrialised countries. Am $\mathcal{F}$ Obstet Gynecol 1980;138:880-92.

Aral SO, Coates W. The increasing concern with infertility-why now? JAMA 1983;250: 2327-31.

West CP, Templeton AA, Lees MM. The diagnostic classification and prognosis of 400 infertile couples. Infertility 1982;5:127-44.

8 Hull MGR, Glazener CMA, Kelly NJ, et al. Population study of causes, treatment and outcome of infertility. Br Med J 1985;291:1693-7.

9 Vessey MP, Wright NH, McPherson K, Wiggins P. Fertility after stopping different methods of contraception. Br Med f 1978;i:265-7.

10 Ross RK, Pike MC, Vessey MP, Bull D, Yeates D, Casagrande JT. Risk factors for uterine fibroids: reduced risk associated with oral contraceptives. $\mathrm{Br} M e d \mathcal{F}$ 1986;293:359-62.

11 Sloan DG. Has fecundability been declining in recent years in developed countries? $\mathrm{F} \mathrm{Biosoc} \mathrm{Sci}$ 1983;15:111-4.

12 Leto S, Frensilli FJ. Changing parameters of donor semen. Fertil Steril 1981;36:766-70.

13 Southam A. What to do with the "normal" infertile couple. Fertil Steril 1960;11:543-9.

13 Templeton AA, Penney GC. The incidence, characteristics and prognosis of patients whose Templeton AA, Penney GC. The incidence, characteristicy is unexplained. Fertil Steril 1982;37:175-82.
infertilitis.

15. Sorensen SS. Infertility factors: their relative importance and share in an unselected material of infertility patients. Acta Obstet Gymecol Scand 1980;59:513-20.

16 Collins JA, Wrixon W, Janes LB, Wilson EH. Treatment-independent pregnancy among infertile couples. N Engl f Med 1983;309:1201-6.

17 Schwartz D, Mayaux MJ, Spira A, et al. Semen characteristics as a function of age in 833 fertile men. Fertil Steril 1983;30:530-5.

18 Federation CECOS, Schwartz D, Mayaux MJ. Female fecundity as a function of age. $N$ Engl $\mathcal{f}$ Med 1982;306:404-6.

19 Metcalf MG. Incidence of ovulatory cycles in women approaching the menopause. $\mathcal{F} \mathrm{Biosoc} S \mathrm{Ci}$ 1979;11:39-48.

20 Edwards RG, Steptoe PC. Current state of in vitro fertilisation and implantation of human embryos. Lancet 1983;ii:1265-9.

21 Gosden RG. Biology of menopause. The causes and consequences of ovarian aging. London: Academic Press, 1985:91-119.

22. Jones HW. The selection of patients for in vitro fertilisation. In: Thomson W, Joyce DN, Newton JR, eds. In vitro fertilisation and donor insemination. London: Royal College of Obstetricians and Gynaecologists 189-96. (Proceedings of the 12th study group of the Royal College of Obstetricians and Gynaecologists.)

23 Menken J, Trussel J, Larken U. Age and infertility. Science 1986;233:1389-94.

\section{Major crush injury}

Crushing injuries produce a wide range of pathological changes: minor and major but short lived ones are generally well managed, though failure to recognise the full extent of the damage may delay healing. Longer term compression of tissues, however, is less well understood.

Limb compression can injure through either ischaemia or muscle destruction,' and, though the end result may be similar, the initial treatment is different. A pressure of 40-60 $\mathrm{mm} \mathrm{Hg}$ will start functional changes in nerves and muscles after 15 minutes ${ }^{2}$ and can lead to ischaemic necrosis within four to eight hours. ${ }^{3}$. Systemic manifestations of muscle damage and necrosis may follow prolonged pressure from a patient's own body weight when he or she is unconscious after a drug overdose $\mathrm{e}^{4}$ or while undergoing an operation. ${ }^{5}$ The necrosis may also result from antishock garments. ${ }^{6}$ Compartmental syndromes, with or without trauma, often go unrecognised because the appearance of the limb may be misleading. Pain, swelling, sensory change, weakness, and pain on passive stretching are present in varying combinations. ${ }^{7}$ Any progressive neurovascular deficit should be determined by clinical examination supported by direct pressure measurement or electrical conductivity testing. These tests are essential, for the longer treatment is delayed the greater the chance of permanent damage. Computed tomography may help to show areas of myonecrosis. ${ }^{5}$ Adequate decompression by fasciotomy or epimysiotomy, or both, is the treatment. The dead limb with imminent or established gangrene should be recognised and treated. Late arterial and nerve reconstruction may salvage length, but function is often severely impaired. ${ }^{8}$
The more severe crush injuries seen in patients trapped often for hours and often from natural disasters must have existed for years. They were mentioned during the first world war, but not until 1941 was the problem satisfactorily described. ${ }^{9}$ The crush syndrome of acute renal failure, infection, ventilatory complications, neuropsychiatric disturbances, stress ulcers, and coagulopathies is now well recognised. For the past 10 years there have been on average two major disasters a year in Britain, all of them different and few of them producing the pattern of injuries associated with earthquakes or warfare.

Major crush injuries damaging more than one system, especially in the trunk or head, are often fatal for rescue is often delayed. ${ }^{10}$ Injuries to the limbs are survivable, and published accounts deal almost exclusively with leg injuries. Since the Moorgate tube disaster in 1975, when two patients died of crush injuries, ${ }^{11}$ only sporadic reports have appeared from Britain. ${ }^{12}$

Muscle severely damaged by entrapment releases its contents into the circulation on being freed. These patients, like those with severe compartment syndromes, have a rising blood urea nitrogen concentration; high serum concentrations of potassium, phosphate, and uric acid; a raised anion gap; a raised packed cell volume, thrombocytopenia, and often myoglobinuria. ${ }^{4}$ Serum creatine kinase activities greater than five times normal are diagnostic of muscle damage in the absence of other injuries. ${ }^{13}$ The high serum potassium concentration, especially if associated with a low serum sodium concentration, may cause cardiac arrhythmias and arrest soon after release. ${ }^{14}$ Recognition of the severe crushing injury is essential, with shock being added to the previously mentioned signs. Peripheral pulses are frequently present initially, giving a false sense of security. Prehospital treatment should be aimed at preserving the sodium concentration during treatment for shock. Analgesics may help reduce the shock and will probably be needed for pain relief. Stewart and others have suggested that a tourniquet should be applied before freeing the limb and not released until arrival in the hospital, but the theory may be easier than the practice. ${ }^{15}$

Treatment has been aimed at preventing the sequelae, and forced alkaline diuresis with bicarbonate and mannitol will help protect the kidneys. ${ }^{16} 17$ Sepsis is the greatest scourge, and closed injuries should be treated conservatively. ${ }^{3} \mathrm{Limb}$ elevation is not recommended. ${ }^{7}$ Open wounds may need complete debridement of all muscle, and even in theatre damage is deceptive in its colour and back bleeding. ${ }^{17}$ Mechanical or electrical stimulation, or both, may be required to tell if the muscle is alive; any dead muscle invites infection and secondary haemorrhage: If a patient with closed injuries deteriorates then extensive fasciotomy and debridement are needed.

Early amputation should be considered in patients with open wounds or in those deteriorating, but there is no single indication, although a ratio of creatine to creatinine greater than $1 \cdot 10$ is a pointer. ${ }^{1}$ Any delay will accentuate the complications. ${ }^{1}$ The morbidity from major crush injuries may still be high, but the mortality should be less than the 60 $70 \%$ of 30 years ago. ${ }^{18}$

I P STEWART

Consultant,

Accident and Emergency Department,

Plymouth General Hospital,

Plymouth PL4 7JJ

1 Santangelo ML, Usberti M, Di Salvo E, et al. A study of the pathology of the crush syndrome. Surg Gymecol Obstet 1982;154:372-4. 